\title{
MODIFICATION OF THE OESTROUS CYCLE OF THE UNDER-FED RAT INDUCED BY THE PROXIMITY OF A MALE
}

\author{
A. S. MaNeILLY, K. J. COOPER AND D. B. GRIGHTON \\ Department of Physiology and Environmental Studies, University of Nottingham \\ School of Agriculture, Sutton Bonington, Loughborough, Leicestershire
}

(Received 29th September 1969)

Dietary restriction in the rat has been shown to affect the oestrous cycle, increasing the length of the di-oestrous period and producing a reduction in the cellular content of the vaginal smear (Mulinos \& Pomerantz, 1940). Cooper \& Haynes (1967) demonstrated that the introduction of a male to the cage of a female rat subjected to dietary restriction resulted in a shortening of the cycle regardless of the stage at which the male was introduced. In those animals which failed to mate at the first oestrus after introduction of the male (detected by the vaginal smear technique), the subsequent cycle again appeared to be of shorter duration than those before the introduction of the male, indicating that the female continued to respond to the presence of the male. The present work was conducted to examine the induced changes in the oestrous cycle under controlled conditions and in more detail.

Eighty nulliparous female rats from a closed colony of Wistar origin were allocated to the experiment. They were 12 weeks old, weighed 120 to $160 \mathrm{~g}$ and had completed at least two normal cycles. The rats were caged individually under a lighting regimen of $12 \mathrm{hr}$ light/12 hr dark, the period of light being from 08.00 to 20.00 hours. The females were allocated randomly into two groups, one of twenty rats on unrestricted feeding and one of sixty rats fed $65 \%$ of the previous mean daily intake of the group on unrestricted feeding. Each group was divided into two equal sub-groups, to one of which males were to be introduced (Text-fig. 1). Daily vaginal smears were prepared from all females, the cycle being classified into the stages, pro-oestrus, oestrus, metoestrus and di-oestrus. Of the animals subjected to dietary restriction, five became anoestrous and were discarded. Males selected for introduction to the cages of the experimental females were of the same strain as the females, 6 to 9 months old and of proven fertility. In order to prevent mating and to differentiate the possible effects of copulatory behaviour from those of male proximity, physical contact was minimized by dividing each cage in half by a $\frac{1}{2}$-in. wire mesh barrier Males were in close proximity to the experimental females for periods of $16 \mathrm{hr}$ in each $24 \mathrm{hr}$ from 17.00 to 09.00 hours. During the day, the males were caged in groups. Each male was marked so that the same individual could be introduced each night into the cage of the same experimental female.

Introduction of the male to the female under dietary restriction was carried 
out as soon as a metoestrous smear was detected in the first cycle to occur following a di-oestrous period of at least 5 days. In the group on unrestricted feeding, introduction of the male was carried out as soon as metoestrus was detected in a normal cycle. Introduction of males to both groups was synchronized as far as possible. After three cycles, daily introduction of the male was terminated for a period of one cycle, following which a second male of the same strain was introduced as before for a period of one cycle. The changes in mean cycle lengths for each group are shown in Text-fig. 1. The significance of differences was assessed by the $t$ test. The introduction of the first male, its removal for one cycle and the subsequent introduction of a second male had no significant effect on the mean cycle lengths of animals on unrestricted feeding (Text-fig. 1, $\mathrm{a}$ and b). The introduction of the first male to the females on restricted diet, however, resulted in a marked reduction in mean cycle length when the mean for the first cycle after introduction in all twenty-seven females to which the male was introduced was compared with the overall mean for

(a)

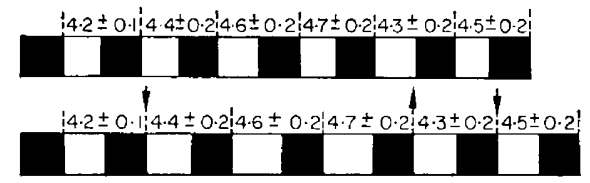

(c)

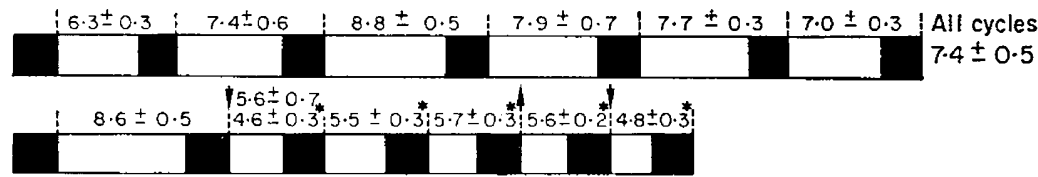

(d)

TEXT-FIG. 1. Cycle lengths (mean \pm S.E.) of rats on the various treatments. (a) Unrestricted feeding, control; (b) unrestricted, male introduced; (c) restricted, control; (d) restricted, male introduced. Arrows indicate male introduced ( $\downarrow$ ) and removed ( $\uparrow$ ) Shaded areas represent pro-oestrus + oestrus + metoestrus, unshaded areas represent di-oestrus. Asterisks indicate that the mean and S.E. were calculated from those animals which showed a reduction in cycle length in response to the introduction of the first male.

control animals (i.e. of six cycles from each of twenty animals) $(P<0.05)$. When the mean cycle length immediately after introduction of the male was compared with the mean length of the last cycle immediately before introduction, there was also a marked reduction $(P<0.001)$. This response occurred in twenty-four out of twenty-seven animals. Of three cycles following the introduction of the male to these twenty-four animals, the third cycle was significantly longer than the first $(P<0.01)$ although all three showed the effect of the proximity of the male in that they were of a shorter duration than those before the introduction of the male. Removal of the male for one cycle did not result in any significant change in cycle length. The introduction of the second male again significantly reduced the mean cycle length compared with the cycle immediately before that introduction $(P<0.05)$ (Text-fig. 1, c and d) although this response was only seen in seventeen out of the twenty-four animals which had shown a shortening of the cycle in response to the introduction of the first male.

The present work confirms and extends the findings of Cooper \& Haynes 
(1967) in that an immediate and marked reduction in the mean oestrous cycle length of female rats subjected to dietary restriction was induced by the proximity of the male. Copulatory behaviour was not a necessary factor in the response. Although the response was less apparent in subsequent cycles, the female appearing to become less sensitive to the proximity of the male, the imposition of a period during which the male was not introduced daily, followed by the random re-introduction of males, resulted in a second demonstration of the response. The effects of physical contact were not completely excluded in this experiment and it is not yet possible to state which factors associated with the presence of the male were responsible for inducing these changes in the cycle.

\section{REFERENCES}

COOPER, K.J. \& HAYNES, N. B. (1967) Modification of the oestrous cycle of the under-fed rat associated with the presence of the male. F. Reprod. Fert. 14, 317.

Mulinos, M. G. \& Pomerantz, L. (1940) Pseudohypophysectomy-a condition resembling hypophysectomy produced by malnutrition. F. Nutr. 19, 439. 